\title{
Ortaokul Öğrencilerinde Anneye Bağlanma ve Benlik Saygısı
}

\author{
Ziya TOPRAK*
}

\begin{abstract}
Öz: Ergenlerde bağlanma ve benlik saygısı ayrı ayrı sıklıkla ele alınan sorunsallar olarak dikkat çekmektedir. Benlik saygısının kişilerin sağlıklı davranış geliştirmesine yardım ettiğini ve psikolojik iyi olma durumlarına olumlu katkı yaptığı iyi bilinen bir olgudur. Benzer şekilde bağlanmanın, özellikle anneye bağlanmanın, benlik saygısının öncülü olduğunu belirten araştırmalar mevcuttur. Bu çalışma bu alan yazına anneye bağlanma ve benlik saygısı arasındaki ilişkiyi inceleyerek eklemlenmektedir. Bu araştırmanın amacı ortaokul öğrencilerinin anneye bağlanma biçimleri ile benlik saygısı düzeyleri arasındaki ilişkiyi incelemektir. İlişkisel desende yapılan bu çalışmada rastgele seçilen 343 öğrencinin sağladığı veriler kullanılmıştır. Çalışmada öğrencilerin anneye bağlanma biçimleri ile benlik saygısı düzeyleri arasında olumlu ilişkiler olduğu tespit edilmiştir. Çalışma, bulgulardan hareketle, anne-çocuk bağlanma programlarının geliştirilmesi ve uygulanmasını önererek sonlanmaktadır.
\end{abstract}

Anahtar Sözcükler: Anneye Bağlanma, Benlik Saygısı, Korelasyon, Ortaokul Öğrencileri

\section{Maternal Attachment and Self-Esteem Among Middle School Students}

\begin{abstract}
Attachment and self-esteem in adolescents attract attention which have gained momentum recently as research problems. There are studies reporting that self-esteem helps individuals to develop healthy behavior and contributes positively to psychological well-being. Similarly, there are studies indicating that attachment, especially attachment to the mother, is an indicator of self-esteem. This study contributes to this literature by examining the relationship between maternal attachment and self-esteem. The aim of this study is to investigate the relationship between middle school students' attachment style and self-esteem levels. In this correlational study, the data provided by 343 randomly selected students is used. It is observed that there are positive relationships between the students' attachment style and self-esteem levels. Based on the findings, the study concludes with the proposition of developing and implementing mother-child attachment programs.
\end{abstract}

Keywords: Maternal Attachment, Self-Esteem, Correlation, Middle School Students

* Beşiktaş Halk Eğitim Merkezi, İstanbul, Türkiye, e-posta: ziya.toprak@boun.edu.tr, ORCID: https://orcid.org/0000-0002-1309-4902 
Bağlanma çalışmaları Bowlby'nin $(1977,1988)$ geliştirdiği kuramsal çerçeveden itibaren oldukça derin araştııılmış bir alan olarak karşımıza çıkmaktadır. Bowlby ile birlikte bağlanmanın önemi kavranılmış ve gerek çocuklarda, gerekse yetişkinlerde bağlanma sorunsalı derinlemesine ve farklı açılardan ele alınmıştır (Cassidy, 1988; Demirtaş, 2019; Günaydın, Selçuk, Sümer ve Uysal, 2005; Kobak ve Sceery, 1988; Mikulincer ve Shaver, 2007; Paterson, Pryor ve Fiedl, 1995; Suzuki ve Tomada, 2015; Varghese ve Pistole, 2017). Tüm çalışmaların ulaştığı bulgular farklı olsa da işaret ettikleri ortak nokta bağlanma biçiminin hem çocuklar hem de yetişkinler üzerinde önemli etkileri olduğudur. Bu çalışmanın diğer sorunsalı olan öz-saygı kavramı da etkileri farklı açılardan incelenmiş bir konu olarak karşımıza çıkmaktadır. Coopersmith'in (1967) öncüllerinden olduğu benlik saygısının birçok farklı pozitif kavram ile olumlu korelasyon gösterdiği ve aracılık ettiği raporlanmaktadır (Demirtaş, 2019; Güloğlu ve Aydın, 2001; Mert ve Tamer, 2019; Suzuki ve Tomada, 2015; Wilkinson, 2004). Bağlanma ve benlik saygısı psikolojik iyiliği ve kişilik gelişimini derinden etkileyen faktörler olarak karşımıza çıkmaktadır, bu bağlamda her iki kavramın ilişkili olduğu sorunsalın ortak olduğunu ifade etmek mümkündür. Bu çalışma bu iki kavram arasında ilişki incelemektedir.

Jonh Bowlby'nin öncüllerinden olduğu bağlanma kuramı gelişim kuramları alanında ön plana çıkan ve ebeveyn bakımının çocuklar üzerindeki etkilerini araştıran bir alandır. Bowlby (1982) psikolojik bir kavram olarak bağlanmanın biyolojik temellerini araştırır ve bağlanmanın davranışsal kontrol sisteminin bir parçası olduğunu ifade eder. Bağlanmanın temel olarak çocuğun tehlike içinde olduğunu hissettiği anlarda bir tür savunma mekanizması olarak işlediğine inanan Bowlby ile birlikte araştırmalar bağlanmanın farklı boyutlarını ortaya koymuştur.

Ainsworth (1989) bağlanma alanında önemli çalışmalar yapmış diğer öncüller arasındadır. Bağlanmaya boyutsal bir yaklaşım getiren Kanadalı araştırmacı bağlanmanın temel olarak üç farklı biçimi olduğunu iddia eder. Güvenli, gerilimli kaçınan ve gerilimli direnç gösteren bu üç boyuta verilen isimlerdir (Ainsworth, Blehar, Waters ve Wall, 1978). Sosyal, Bodur, İşleri ve Şenol (2005) bebeklerde bağlanma konusunu işledikleri çalışmalarında adı geçen üç boyutu ele alırlar:

\footnotetext{
Güvenli bağlanma (secure attachment) geliştiren bebekler, birincil bağlanma objeleri yanlarında olmadığı koşullarda, çevreyi araştırıp, yakınlığı koruyabilen ve bakıcısını güvence üssü olarak kullanabilme becerisine sahiptirler. Ebeveynin gidişine tepki gösterirler. Ancak, protesto davranışı, anne-babanın geri dönüşüyle birlikte yerini rahatlama ve araştırıcı davranışlara bırakmaktadır.

Gerilimli kaçınan bağlanma (anxious-avoidant attachment) geliştiren bebekler, bakıcıları ile birlikteyken araştırıcı davranışlara devam edip duygularını bu kişi ile paylaşmamaktadırlar. Ancak, bakıcıları herhangi bir şekilde ortamdan ayrılıp geri döndüğünde, hiçbir değişiklik olmamış gibi meşgul oldukları işe dikkatlerini yöneltirler.

Gerilimli direnç gösteren bağlanma (anxious-resistant attachment) geliştiren bebekler, bakıcıları yanlarındayken diğer kişilerle ve çevreleriyle ilgilenirler. Ancak, herhangi bir ayrılık durumunun hemen ardından hem bakıcıları ile bir arada olmak hem de ondan uzaklaşmak istemektedirler (s.94-95).
}

Ainsworth'un çalışmalarından sonra bağlanma konusu hep çok boyutlu bir sorunsal olarak ele alınmıştır. Raja, McGee ve Stanton (1992) 935 ergen ile yaptıkları çalışmalarında bağlanmayı iletişim, güven ve yabancılaşma boyutları üzerinden değerlendirirler. Yazarlar çalışmalarında Armsden ve Greenberg'in (1987) geliştirdiği kavramsal çerçeveyi kullanırlar. Buna göre güven, ergenin annesinin ve babasının onun istek ve arzularını anladıklarına ve onlara saygı duyduklarına ilişkin ebeveynlerine duyduğu güveni; sözel iletişimin kalitesini ölçen iletişim boyutu ergenin anne ve babasının onun duygusal durumlarına hassaslığını ve yabancılaşma ise ergenin anne ve babası ile ilişkisinde izolasyon, kızgınlık ve kopma gibi duygularını ifade etmektedir (Guarnieri, Ponti ve Tani, 2010, s. 105). Bu araştırma da benzer kavramsal çerçeve kullanılmaktadır. Çalışmada Günaydın, Selçuk, Sümer ve Uysal'ın (2005) Türkçeleştirdiği Raja ve diğerlerinin (1992) geliştirdiği kısa bağlanma formu kullanılmaktadır.

Benlik saygısı kişilik değişkenlerinden biri olarak ele alınmakta ve kişinin akademik, sosyal ve özel hayatını etkileme potansiyel yüksek olan bir değişken olarak değerlendirilmektedir. Benlik saygısını temel olarak kişinin kendisinden duyduğu memnuniyet veya tatmin olarak anlamak mümkündür. Benlik saygısı, kişinin kendi dış görünüşüne, kişilik özelliklerine ve psikolojik özelliklerine ilişkin algısının bir ifadesidir. “Coopersmith'e (1967) göre özsaygı bireyin kendini yetenekli, önemli, başarılı ve değerli olarak algılama 
derecesidir. Rosenberg'in (1965) önermiş, olduğu tanımlamada 'özsaygı, kendimize karşı olan olumlu ve olumsuz tutumlarımızdır' denilmektedir. Yörükoğlu (1996) ise özsaygıyı 'kendini olduğundan aşağı ya da olduğundan üstün görmeksizin kendinden memnun olmayı, kendini olduğu gibi kabullenmeyi, özüne güvenmeyi sağlayan sağlıklı bir ruh hali' olarak tanımlamaktadır." (akt. Güloğlu ve Aydın, 2001, s. 66). Dolayısı ile benlik saygısını kişinin kendisi ile ilişki kurma biçimi olarak değerlendirmek ve bu ilişki kurma biçiminin kişinin diğer ilişkilenme biçimlerini derinden etkileyebileceğini varsaymak mümkündür. Kişinin kendisi ile ilişkili yaptığı değerlendirmelerin toplamı olan ve bireyin psikolojik ve bilişsel gelişimini etkileyen benlik saygısının psikolojik sağlık, fizyolojik sağlık, sosyal etkileşim, akademik başarı gibi birçok farklı değişkenle korelasyon içerisinde olduğu çeşitli araştırmalar tarafından raporlanmaktadır (Harter, 2012; Thompson, 2008). Kişilik gelişiminde bu kadar önemli olan benlik saygısının öncülleri oldukça önem kazanmaktadır. Bağlanma kuramının benlik saygısı ilişkisinin belirlenmesinin önemi bu açıdan bakıldığında açık gözükmektedir.

Aile kişinin kendisine dair geliştirdiği kendilik algısını etkileyen en önemli değişkenlerden biridir. Bağlanma kuramına göre bağlanmanın, özellikle anneye bağlanmanın, benlik saygısı üzerinde önemli etkileri vardır (Ainsworth, 1989; Burke ve Weir, 1978; Öztürk, 2017). Yine güvenli bağlanmanın psikopatolojik rahatsızlıklara karşı koruyucu etkisi olduğunu ve kabul edilebilir seviyede benlik saygısının gelişimine katkıda bulunduğunu raporlayan araştırmalar mevcuttur (Cassidy, 1988; Parker ve Benson, 2004). Bağlanma ile benlik saygısı arasındaki ilişkinin ele alındığı araştırmalarda özellikle anne ile kurulan ilişkinin kalitesi ön plana çıkmaktadır (Cassidy, 1988; Graybill, 1978; Keskin, 2014; Paulusa, Licata, Ginewosz ve Sodian, 2018). Dolayısı ile anne ile kurulan ilişkinin kalitesi benlik saygısının öncülü konumundadır. Bu çalışma bu varsayımı test etmektedir. Benlik saygısının kişilik gelişiminde oynadığı rolü düşününce öncülünün saptanması oldukça önemli gözükmektedir. Benlik saygısı yüksek olan bireylerin hem kendileri açısından hem de toplumsal açıdan daha sağlıklı ve kabul edilebilir davranışlar içeresinde olacakları açıtır. Bu bağlamda kişilerin benlik saygısını ve bu saygının öncülü olarak anne ile kurulan ilişkinin içeriği ile ilişkisinin belirlemek bu araştırmanın temel amacıdır. Bu amaç doğrultusunda araştırma kapsamında şu sorulara yer verilmiştir;

1. Ortaokul öğrencilerinin anneye bağlanma tarzları ve benlik saygıları hangi seviyededir?

2. Ortaokul öğrencilerinin anneye bağlanma tarzları ve benlik saygıları cinsiyetlerine ve sınıflarına göre farklılık göstermekte midir?

3. Ortaokul öğrencilerinin anneye bağlanma tarzları ile benlik saygıları arasında anlamlı bir ilişki var midır?

\section{Yöntem}

Ortaokul öğrencilerinin anneye bağlanma tarzları ile benlik saygıları arasındaki ilişkiyi inceleyen bu araştırmada ilişkisel tarama modeli kullanılmıştır (Williams, 2007).

\section{Evren-Örneklem}

Araştırmanın evreni İstanbul'da devlet ortaokullarında okuyan öğrencilerden oluşmaktadır. Araştırma kapsamında 5. sınıflar yaşları küçük olduğundan alınmamıştır. 5. sınıflar ilgili literatürde ergen olarak kabul edilmemektedirler (Giedd ve diğerleri, 1999; Naveh-Benjamin ve diğerleri, 2009). Araştırmanın yapıldığı 2018 yılında Milli Ĕ̆itim Bakanlığı (MEB) verilerine göre 600.000 ortaokul öğrencisi bulunmaktadır (MEB, 2019). Araştırma örnekleminin güvenirlilik seviyesini sağlamak için örnekleme üç farklı bölgeden seçilen (Beşiktaş, Kağıthane, Sultangazi) rastgele seçilen toplam 400 öğrenci dahil edilmiştir. Öğrencilerden verileri tam olan 343 katılımcının verileri analiz edilmiştir. Tablo 1 örnekleme ilişkin bilgileri sunmaktadır.

Tablo I

Katılımcıların Bă̆ımsız Değiş̧kenlere Göre Dağılımı

\begin{tabular}{llll}
\hline & & $\mathrm{f}$ & $\%$ \\
\hline \multirow{3}{*}{ Cinsiyet } & Erkek & 173 & 50.4 \\
& K1z & 170 & 49.6 \\
& Toplam & 343 & 100 \\
\hline
\end{tabular}




\begin{tabular}{llll}
\hline \multirow{3}{*}{ Sinif } & 6. Sinif & 118 & 34.4 \\
& 7. Sinif & 110 & 32.1 \\
& 8. Sinif & 115 & 33.5 \\
& Toplam & 343 & 100 \\
\hline
\end{tabular}

Tablo 1'den izleneceği üzere araştırmaya katılan öğrencilerin \%50.4'ünü (173) erkeler ve \%49.6'sını (170) kızlar oluşturmaktadır. Öğrencilerin \%34.4'ü (118) 6. sınıfa, \%32.1'i (110) 7. sınıfa ve \%33.5'i (115) 8. sinıfa gitmektedir. Genel olarak bağımsız değişkenlere göre örneklem dağılımının dengeli olduğu söylenebilir.

\section{Veri Toplama Araçları}

Araştırmada veri toplama araçları olarak Coopersmit Özsaygı Envanteri (CÖE) ve Ebeveyn ve Arkadaşlara Bağlanma Envanteri (EABE) kullanılmıştır.

CÖE. İlk defa Stanley Coopersmith (1967) tarafından geliştirilen ölçek çeşitli revizyonlara uğrayarak bugünkü halini almıştır. Ölçekte Genel Saygı, Sosyal Özsayg1 Ev-Aile Özsaygı, Okul-Akademik Özsaygı olmak üzere dört alt boyut mevcuttur. Ölçeğin Türkçe uyarlaması farklı araştırmacılar tarafından defaten yapılmıştır (Güçray 1989, Güloğlu ve Aydın, 2001; Turan ve Tufan, 1987). Bu çalışmada Güloğlu ve Aydın (2001) versiyonu kullanılmıştır. Yazarlar çalışmalarında envanterin iç tutarlılık kat sayısını .84 olarak bulmuşlardır. Ölçekten alınan ve alt boyutlardan alınan yüksek puanlar öz güvenin ve ilgili alt boyuta ilişkin özgüvenin yüksekliğini işaret etmektedir.

EABE. Orijinali 28 maddeden oluşan ve Armsden ve Greenberg (1987) tarafından geliştirilen envanterin Türkçeleştirilmesi Raja ve diğerleri (1992) tarafından geliştirilen kısa form üzerinden olmuştur. Ölçeğin Güven, İletişim ve Yabancılaşma olmak üzere üç alt boyutu mevcuttur. Kısa formun Türkçe adaptasyon çalışması Günaydın ve diğerleri (2005) tarafından gerçekleştirilmiştir. Yazarlar çalışmalarında anne formunun iç tutarlılık kat sayısını .88 olarak bulmuşlardır. Bu çalışmada 12 maddeden oluşan ölçeğin anne formu kullanılmıştır.

\section{Veri Analizi}

Araştırma kapsamında toplanan verilerin normal dağıldığı belirlendikten sonra analizlerde parametrik testler kullanılmıştır. SPSS 24 programı kullanılarak gruplar arası farkları belirlemek için bağımsız değişken t-testi ve ANOVA ve değişkenler arasındaki ilişkilerin tespiti için Pearson Korelasyon Katsayısı kullanılmıştır.

\section{Bulgular}

Çalışmanın birinci alt problemi katılımcıların bağlanma tarzlarının ve benlik saygısı seviyelerinin belirlenmesine ilişkindir. Tablo 2' de katılımcıların bu değişkenlerden aldıkları puanlar izlenmektedir.

\section{Birinci Alt Probleme İlişkin Bulgular}

\section{Tablo II}

Katılımcıların Bağlanma Tarzlar ve Benlik Saygıları

\begin{tabular}{lccc}
\hline & $\mathrm{N}$ & $\overline{\mathrm{X}}$ & $\mathrm{ss}$ \\
\hline Güven & 343 & 5.69 & 1.28 \\
İletişim & 343 & 4.62 & 1.26 \\
Yabancılaşma & 343 & 5.08 & 1.48 \\
Toplan Bağlanma Puanı & 343 & 5.13 & 1.12 \\
Genel Özsayg1 & 343 & 40.19 & 3.52 \\
Sosyal Özsayg1 & 343 & 11.83 & 1.39 \\
Ev-Aile Özsayg1 & 343 & 11.97 & 1.40 \\
Okul-Akademik Özsayg1 & 343 & 12.03 & 1.69
\end{tabular}

Tablo 2' de katılımcıların toplam bağlanma puanların, bağlanma alt boyutlarından alınan puanların, benlik saygisı alt boyutlarından alınan puanların ortalamaları izlenmektedir. Tablodan izlenen puanların yüksekliği ilgili boyutun yüksekliği anlamına gelmektedir. Bağlanma ile ilgili alınabilecek en yüksek ortalamanın en fazla 7 olabileceğini belirtmekte gerekir. Buna göre katılımcıların güvenli bağlanma alt boyutundan aldıkları puanların ortalaması yüksek seviyededir $(\overline{\mathrm{X}}=5.69, \mathrm{ss}=1.28)$. Benzer şekilde iletişim boyutundan alınan ortalama 
puan tatmin edici seviyededir $(\overline{\mathrm{X}}=4.62$, ss=1.26). Ters puanlanan yabancılaşma alt boyutu da yüksek seviyededir $(\overline{\mathrm{X}}=5.08, \mathrm{ss}=1.48)$. Katılımcıların toplam bağlanma puanları ortalamaları da yüksek seviyededir $(\bar{X}=5.13$, ss=1.12). Benlik saygısı envanterinden alınan puanların ortalama üzeri olduğu dikkat çekmektedir. Envanterin genel özsaygı boyutundan alınabilecek azami puan 56 iken, diğer boyutların azami puan 16'dır. Buna göre katılımcıların genel özsaygı ortalamaları 40.19 ( $\mathrm{ss}=3.52$ ), sosyal özsaygı ortalamaları 11.83 ( $\mathrm{ss}=1.39$ ), ev-aile özsaygı ortalamaları 11.97 (ss=1.40) ve okul-akademik özsaygı ortalamaları 12.03 (ss=1.69) olarak gerçekleşmiştir.

\section{İkinci Alt Probleme İlişkin Bulgular}

Çalışmanın ikinci alt problemi katılımcıların bağlanma tarzlarının ve benlik saygılarının sınıfa ve cinsiyete göre farklılık gösterip göstermediği ile ilgilidir. Katılımcıların cinsiyete göre farklılıkları bağımsız örneklem ttesti ve sınıflara göre farklılıkları tek yönlü varyans analizi testi ile incelenmiştir. Tablo 3 'te kalıtımcıların bağlanma tarzlarının ve benlik saygılarının cinsiyetlerine göre farkına bakılmıştır.

Tablo III

Katılımcıların Bă̆lanma Tarzları ve Benlik Saygıları Ortalamalarının Cinsiyetlerine Göre Farklılıkları

\begin{tabular}{|c|c|c|c|c|c|c|c|}
\hline & Cinsiyet & $\mathrm{N}$ & $\overline{\mathrm{X}}$ & SS & Stand. Hata Fark1 & $\mathrm{t}$ & $\mathrm{p}$ \\
\hline \multirow{2}{*}{ Güvenli Bağlanma } & Erkek & 173 & 5.70 & 1.22 & \multirow{2}{*}{.88} & \multirow{2}{*}{.145} & \multirow{2}{*}{.885} \\
\hline & $\mathrm{K} 1 \mathrm{z}$ & 170 & 5.68 & 1.33 & & & \\
\hline \multirow{2}{*}{ İletişim } & Erkek & 173 & 4.66 & 1.22 & \multirow{2}{*}{.58} & \multirow{2}{*}{.541} & \multirow{2}{*}{.589} \\
\hline & $\mathrm{K} 1 \mathrm{z}$ & 170 & 4.59 & 1.30 & & & \\
\hline \multirow{2}{*}{ Yabancılaşma } & Erkek & 173 & 5.07 & 1.47 & \multirow{2}{*}{.83} & \multirow{2}{*}{.209} & \multirow{2}{*}{.835} \\
\hline & $\mathrm{K} 1 \mathrm{z}$ & 170 & 5.10 & 1.50 & & & \\
\hline \multirow{2}{*}{ Toplam Bağlanma Puanı } & Erkek & 173 & 5.14 & 1.07 & \multirow{2}{*}{.86} & \multirow{2}{*}{.166} & \multirow{2}{*}{.868} \\
\hline & $\mathrm{K} 1 \mathrm{z}$ & 170 & 5.12 & 1.16 & & & \\
\hline \multirow{2}{*}{ Sosyal Özsayg1 } & Erkek & 173 & 11.77 & 1.49 & \multirow{2}{*}{.50} & \multirow{2}{*}{.674} & \multirow{2}{*}{.501} \\
\hline & $\mathrm{K}_{12}$ & 170 & 11.88 & 1.29 & & & \\
\hline \multirow{2}{*}{ Ev-Aile Özsayg1 } & Erkek & 173 & 11.87 & 1.42 & \multirow{2}{*}{.15} & \multirow{2}{*}{1.41} & \multirow{2}{*}{.157} \\
\hline & $\mathrm{K}_{1 z}$ & 170 & 12.08 & 1.38 & & & \\
\hline \multirow{2}{*}{ Okul-Akademik Özsayg1 } & Erkek & 173 & 11.84 & 1.56 & \multirow{2}{*}{.035} & \multirow{2}{*}{2.12} & \multirow{2}{*}{.035} \\
\hline & $\mathrm{K}_{12}$ & 170 & 12.22 & 1.79 & & & \\
\hline \multirow{2}{*}{ Genel Özsayg1 } & Erkek & 173 & 40.09 & 3.43 & \multirow{2}{*}{.59} & \multirow{2}{*}{.530} & \multirow{2}{*}{.597} \\
\hline & $\mathrm{K} 1 \mathrm{z}$ & 170 & 40.29 & 3.61 & & & \\
\hline
\end{tabular}

Tablo 3'te cinsiyete farkları incelemek için gerçekleştirilen bağımsız örneklem t-testi sonuçları izlenmektedir. Buna göre öğrencilerin cinsiyetlerine göre güvenli ortalamaları arasında anlamlı bir fark bulunmamıştır ( $\left.\overline{\mathrm{X}}_{\text {erkek }}=5.70, \mathrm{ss}=1.22, \overline{\mathrm{X}}_{\mathrm{k} z}=5.68, \mathrm{ss}=.1 .33, \mathrm{p}=.885\right)$. Benzer şekilde katılımcıların cinsiyetlerine göre iletişim ( $\overline{\mathrm{X}}_{\text {erkek }}=4.66, \mathrm{ss}=1.22, \overline{\mathrm{X}}_{\mathrm{k} \mathrm{z}}=4.59$, ss=1.30, $\left.\mathrm{p}=.589\right)$, yabancllaşma ortalamaları $\left(\overline{\mathrm{X}}_{\text {erkek }}=5.07, \mathrm{ss}=1.47 \overline{\mathrm{X}}_{\mathrm{kz}}=5.10\right.$, $\mathrm{ss}=1.50, \mathrm{p}=.835)$, ve toplam bağlanma ortalamaları $\left(\overline{\mathrm{X}}_{\text {erkek }}=5.14\right.$, ss=1.07 $\left.\overline{\mathrm{X}}_{\mathrm{kz}}=5.12, \mathrm{ss}=1.16, \mathrm{p}=.868\right)$ arasında da anlamlı bir fark bulunamamıştır. Katılımciların cinsiyetlerine göre sosyal özsaygı ( $\overline{\mathrm{X}}_{\text {erkek }}=11.77, \mathrm{ss}=1.49$, $\overline{\mathrm{X}}_{\mathrm{k} \mathrm{z}}=11.88$, ss=1.29, $\left.\mathrm{p}=.501\right)$, ev-aile sayg1 ( $\left.\overline{\mathrm{X}}_{\mathrm{erkek}}=11.87, \mathrm{ss}=1.42, \overline{\mathrm{X}}_{\mathrm{k} \mathrm{z}}=12.08, \mathrm{ss}=1.38, \mathrm{p}=.157\right)$ ve genel özsayg1 $\left(\overline{\mathrm{X}}_{\text {erkek }}=40.09, \mathrm{ss}=3.43, \overline{\mathrm{X}}_{\mathrm{k} z}=40.29, \mathrm{ss}=3.61, \mathrm{p}=.567\right)$ ortalamaları arasında anlamlı bir fark bulunmamıştır. Katılımcıların cinsiyetlerine göre okul-akademik özsaygı ortalamaları arasında anlamlı bir fark bulunmuştur. $\left(\bar{X}_{\text {erkek }}=11.84, \mathrm{ss}=1.56, \overline{\mathrm{X}}_{\mathrm{k} z}=12.22\right.$, ss=1.79, $\left.\mathrm{p}=.035\right)$. Tablodan kız çocuklarının okul ile ilgili özsaygılarının anlamlı bir şekilde daha yüksek olduğu izlenmektedir.

Tablo IV

Katılımcıların Bağlanma Tarzları ve Benlik Saygıları Ortalamalarının Sımıflarına Göre Farklılıkları

\begin{tabular}{|c|c|c|c|c|c|c|c|}
\hline & & Kareler. Toplamı & $\mathrm{sd}$ & Kareler Ort. & $\mathrm{F}$ & $\mathrm{p}$ & Gruplar (Ort. fark1) \\
\hline \multirow{3}{*}{ Güvenli Bağlanma } & Gruplar Arası & 12.274 & 2 & 6.137 & 3.827 & .023 & $6-7(.45)$ \\
\hline & Grup İçi & 545.218 & 340 & 1.604 & & & \\
\hline & Toplam & 557.492 & 342 & & & & \\
\hline \multirow{3}{*}{ İletişim } & Gruplar Arası & 40.103 & 2 & 20.051 & 13.543 & .000 & $6-7(.82)$ \\
\hline & Grup İçi & 503.379 & 340 & 1.481 & & & $6-8(.55)$ \\
\hline & Toplam & 543.482 & 342 & & & & \\
\hline \multirow{2}{*}{ Yabancılaşma } & Gruplar Arası & 45.780 & 2 & 22.890 & 10.970 & .000 & $6-7(.88)$ \\
\hline & Grup İçi & 709.476 & 340 & 2.087 & & & $6-8(.56)$ \\
\hline
\end{tabular}




\begin{tabular}{|c|c|c|c|c|c|c|c|}
\hline & Toplam & 755.257 & 342 & & & & \\
\hline \multirow{3}{*}{ Toplam Bağlanma } & Gruplar Arası & 30.590 & 2 & 15.295 & 13.121 & .000 & $6-7(.72)$ \\
\hline & Grup İçi & 396.335 & 340 & 1.166 & & & $6-8(.48)$ \\
\hline & Toplam & 426.925 & 342 & & & & \\
\hline \multirow{3}{*}{ Sosyal Özsayg1 } & Gruplar Arası & 8.203 & 2 & 4.102 & 2.109 & .123 & \\
\hline & Grup İçi & 661.301 & 340 & 1.945 & & & \\
\hline & Toplam & 669.504 & 342 & & & & \\
\hline \multirow{3}{*}{ Ev-Aile Özsayg1 } & Gruplar Arası & 27.281 & 2 & 13.641 & 7.141 & .001 & $7-8(-.69)$ \\
\hline & Grup İçi & 649.483 & 340 & 1.910 & & & \\
\hline & Toplam & 676.764 & 342 & & & & \\
\hline \multirow{3}{*}{ Okul-Akademik Özsayg1 } & Gruplar Arası & 51.497 & 2 & 25.749 & 9.452 & .000 & $6-8(-.79)$ \\
\hline & Grup İçi & 926.211 & 340 & 2.724 & & & $7-8(-.85)$ \\
\hline & Toplam & 977.708 & 342 & & & & \\
\hline \multirow{3}{*}{ Genel Özsayg1 } & Gruplar Arası & 152.380 & 2 & 76.190 & 6.343 & .002 & $6-7(1.24)$ \\
\hline & Grup İçi & 4083.678 & 340 & 12.011 & & & $7-8(-1.56)$ \\
\hline & Toplam & 4236.058 & 342 & & & & \\
\hline
\end{tabular}

Tablo 5'ten öğrencilerin sınıflarına göre bağlanma düzeyleri ve benlik saygıları puanları arasındaki farkı incelemek için gerçekleştirilen tek-yönlü ANOVA sonuçları izlenmektedir. Buna göre öğrencilerin güvenli bağlanma düzeyleri arasında anlamlı bir fark oluşmuştur ( $\mathrm{F}=3.827, \mathrm{p}=.023)$. Bonferrini testine göre bu fark 6 . sınıflar ile 7. sınıflar arasında gerçekleşmiştir $\left(\overline{\mathrm{X}}_{\text {farkı }}=.45, \mathrm{p}=.024\right)$. Öğrencilerin iletişim düzeyleri arasında anlamlı bir fark oluşmuştur $(\mathrm{F}=13.543, \mathrm{p}<.000)$. Bonferrini testine göre bu fark 6. sinıflar ile 7. sinıflar $\left(\overline{\mathrm{X}}_{\text {fark }}=.82\right.$, $\mathrm{p}<.000)$ ve 6. sinıflar ile 8. sinıflar $\left(\overline{\mathrm{X}}_{\text {fark }}=.55, \mathrm{p}=.002\right)$ arasında gerçekleşmiştir. Öğrencilerin yabancılaşma düzeyleri arasında anlamlı bir fark oluşmuştur $(\mathrm{F}=10.970, \mathrm{p}<.000)$. Bonferrini testine göre bu fark 6 . sinıflar ile 7. sinıflar $\left(\overline{\mathrm{X}}_{\text {fark }}=.88, \mathrm{p}<.000\right)$ ve 6. sinıflar ile 8. sinıflar $\left(\overline{\mathrm{X}}_{\text {farkı }}=.56, \mathrm{p}=.009\right)$ arasında gerçekleşmiştir. Öğrencilerin toplam bağlanma düzeyleri arasında anlamlı bir fark oluşmuştur $(\mathrm{F}=13.121, \mathrm{p}<.000)$. Bonferrini testine göre bu fark 6. siniflar ile 7. siniflar $\left(\overline{\mathrm{X}}_{\text {fark }}=.72, \mathrm{p}<.000\right)$ ve 6. siniflar ile 8. siniflar $\left(\overline{\mathrm{X}}_{\text {farkı }}=.48, \mathrm{p}=.002\right)$ arasında gerçekleşmiştir.

Öğrencilerin sınıflarına göre benlik saygıları düzeyleri arasında da anlamlı farklar bulunmuştur. Buna göre öğrencilerin ev-aile özsaygı düzeyleri arasında anlamlı bir fark oluşmuştur ( $F=7.141, p=.001)$. Bonferrini testine göre bu fark 7. sinıflar ile 8. sinıflar arasında gerçekleşmiştir ( $\left.\overline{\mathrm{X}}_{\text {farkı }}=-.69, \mathrm{p}=.001\right)$. Öğrencilerin okulakademik özsaygı düzeyleri arasında anlamlı bir fark oluşmuştur $(\mathrm{F}=9.452, \mathrm{p}<.000)$. Bonferrini testine göre bu fark 6. sinuflar ile 8. sinıflar ( $\left.\overline{\mathrm{X}}_{\text {fark }}=-.79, \mathrm{p}=.001\right)$ ve 7. siniflar ile 8. siniflar $\left(\overline{\mathrm{X}}_{\text {fark }}=-.85, \mathrm{p}<000\right)$ arasinda gerçekleşmiştir. Öğrencilerin genel özsaygı düzeyleri arasında anlamlı bir fark oluşmuştur ( $\mathrm{F}=6.343, \mathrm{p}=.002)$. Bonferrini testine göre bu fark 6. sinuflar ile 7. sinıflar $\left(\overline{\mathrm{X}}_{\text {farkı }}=1.24, \mathrm{p}=.022\right)$ ve 7. Sinıflar ile 8. Sinıflar $\left(\overline{\mathrm{X}}_{\text {fark }}=\right.$ 1.56, $\mathrm{p}=.002$ ) arasında gerçekleşmiştir. Öğrencilerin sosyal özsaygı düzeyleri arasında anlamlı bir fark oluşmamıştır ( $\mathrm{F}=2.109, \mathrm{p}=.123)$.

\section{Üçüncü Alt Probleme İlişkin Bulgular}

Çalışmanın üçüncü alt problemi öğrencilerin bağlanma tarzları ve benlik saygıları düzeyleri arasındaki ilişki ile ilgilidir. Tablo 5'te bu ilişki izlenmektedir.

Tablo V

Katılımcıların Bağlanma Tarzları ve Benlik Saygısı Düzeyleri Arasındaki İlişki

\begin{tabular}{|c|c|c|c|c|c|c|c|c|c|}
\hline & & Güven & İletişim & Yabancılaşma & $\begin{array}{c}\text { Toplam } \\
\text { Bağlanma }\end{array}$ & Sosyal & Ev-Aile & $\begin{array}{c}\text { Okul } \\
\text { Akademik }\end{array}$ & $\begin{array}{c}\text { Genel } \\
\text { Özsayg1 }\end{array}$ \\
\hline \multirow{3}{*}{ Güven } & $\mathrm{r}$ & 1 & $.467^{* *}$ & $.532^{* *}$ & $.792^{* *}$ & $.123^{*}$ & $.166^{* *}$ & $.208^{* *}$ & $.252^{* *}$ \\
\hline & $\mathrm{p}$ & & .000 & .000 & .000 & .023 & .002 & .000 & .000 \\
\hline & $\mathrm{N}$ & 343 & 343 & 343 & 343 & 343 & 343 & 343 & 343 \\
\hline \multirow{3}{*}{ İletişim } & $\mathrm{r}$ & $.467^{* *}$ & 1 & $.610^{* *}$ & $.824^{* *}$ & $.108^{*}$ & $.208^{* *}$ & $.271^{* *}$ & $.161^{* *}$ \\
\hline & $\mathrm{p}$ & .000 & & .000 & .000 & .047 & .000 & .000 & .003 \\
\hline & $\mathrm{N}$ & 343 & 343 & 343 & 343 & 343 & 343 & 343 & 343 \\
\hline \multirow{3}{*}{ Yabancılaşma } & $\mathrm{r}$ & $.532^{* *}$ & $.610^{* *}$ & 1 & $.875^{* *}$ & .090 & $.135^{*}$ & $.249^{* *}$ & $.203^{* *}$ \\
\hline & $\mathrm{p}$ & .000 & .000 & & .000 & .096 & .012 & .000 & .000 \\
\hline & $\mathrm{N}$ & 343 & 343 & 343 & 343 & 343 & 343 & 343 & 343 \\
\hline \multirow{2}{*}{ Toplam Bağlanma } & $\mathrm{r}$ & $.792^{* *}$ & $.824^{* *}$ & $.875^{* *}$ & 1 & $.127^{*}$ & $.202^{* *}$ & $.292^{* *}$ & $.247^{* *}$ \\
\hline & $\mathrm{p}$ & .000 & .000 & .000 & & .018 & .000 & .000 & .000 \\
\hline
\end{tabular}


Ortaokul Öğrencilerinde Anneye Bağlanma...

\begin{tabular}{|c|c|c|c|c|c|c|c|c|c|}
\hline & $\mathrm{N}$ & 343 & 343 & 343 & 343 & 343 & 343 & 343 & 343 \\
\hline \multirow{3}{*}{ Sosyal } & $\mathrm{r}$ & $.123^{*}$ & $.108^{*}$ & .090 & $.127^{*}$ & 1 & $.372^{* *}$ & $.251^{* *}$ & $.209^{* *}$ \\
\hline & $\mathrm{p}$ & .023 & .047 & .096 & .018 & & .000 & .000 & .000 \\
\hline & $\mathrm{N}$ & 343 & 343 & 343 & 343 & 343 & 343 & 343 & 343 \\
\hline \multirow{3}{*}{ Ev-Aile } & $\mathrm{r}$ & $.166^{* *}$ & $.208^{* *}$ & $.135^{*}$ & $.202^{* *}$ & $.372^{* *}$ & 1 & $.331^{* *}$ & $.315^{* *}$ \\
\hline & $\mathrm{p}$ & .002 & .000 & .012 & .000 & .000 & & .000 & .000 \\
\hline & $\mathrm{N}$ & 343 & 343 & 343 & 343 & 343 & 343 & 343 & 343 \\
\hline \multirow{3}{*}{ Okul-Akademik } & $\mathrm{r}$ & $.208^{* *}$ & $.271^{* *}$ & $.249^{* *}$ & $.292^{* *}$ & $.251^{* *}$ & $.331^{* *}$ & 1 & $.244^{* *}$ \\
\hline & $\mathrm{p}$ & .000 & .000 & .000 & .000 & .000 & .000 & & .000 \\
\hline & $\mathrm{N}$ & 343 & 343 & 343 & 343 & 343 & 343 & 343 & 343 \\
\hline \multirow{3}{*}{ Genel Özsayg1 } & $\mathrm{r}$ & $.252^{* *}$ & $161^{* *}$ & $.203^{* *}$ & $.247^{* *}$ & $.209^{* *}$ & $.315^{* *}$ & $.244^{* *}$ & 1 \\
\hline & $\mathrm{p}$ & .000 & .003 & .000 & .000 & .000 & .000 & .000 & \\
\hline & $\mathrm{N}$ & 343 & 343 & .343 & 343 & .343 & 343 & 343 & 343 \\
\hline
\end{tabular}

Tablo 5'te dikkat çeken ilk nokta envanterlerin kendi içlerin yüksek bir tutarlılık ile pozitif ilişkiler üretmesidir. Buna göre güvenli bağlanma ile sırası ile iletişim $(\mathrm{r}=.467, \mathrm{p}<.000)$, yabancılaşma $(\mathrm{r}=.532, \mathrm{p}<.000)$ ve toplam bağlanma $(\mathrm{r}=.792, \mathrm{p}<.000)$ arasında pozitif yönde orta ve orta üstü kuvvette anlamlı ilişkiler mevcuttur. İletişim ile sırası ile yabancılaşma $(\mathrm{r}=.610, \mathrm{p}<.000)$, ve toplam bağlanma $(\mathrm{r}=.824, \mathrm{p}<.000)$ arasında pozitif yönde orta ve orta üstü kuvvette anlamlı ilişkiler mevcuttur. Son olarak yabancılaşma ile toplam bağlanma arasında da olumlu yönde kuvvetli bir ilişki bulunmaktadır ( $\mathrm{r}=.875, \mathrm{p}<.000)$. Benlik saygısı envanterinde ise zayıf kuvvette de olsa olumlu ilişkiler dikkat çekmektedir. Buna göre sosyal özsaygı ile sırası ile ev-aile $(\mathrm{r}=.372, \mathrm{p}<.000)$, okul-akademik $(\mathrm{r}=.251, \mathrm{p}<.000)$ ve genel sayg1 $(\mathrm{r}=.209, \mathrm{p}<.000)$ boyutlar arasında pozitif yönde zayıf kuvvette anlamlı ilişkiler mevcuttur. Ev-aile boyutu ile sırası ile okul-akademik (r=.331, $\mathrm{p}<.000)$, ve genel özsayg1 $(\mathrm{r}=.315, \mathrm{p}<.000)$ boyutları arasında pozitif zayıf kuvvette anlamlı ilişkiler mevcuttur. Son olarak okul-akademik boyut ile genel özsaygı boyutu arasında da olumlu yönde kuvvetli bir ilişki bulunmaktadır $(\mathrm{r}=.244, \mathrm{p}<.000)$.

Bağlanma tarzları ile özsaygı boyutları arasında zayıf kuvvette de olsa olumlu ilişkiler bulunmaktadır. Buna göre güvenli bağlanma ile sırası ile sosyal ( $\mathrm{r}=.123, \mathrm{p}=.023)$, ev-aile ( $\mathrm{r}=.166, \mathrm{p}=.002)$, okul-akademik ( $\mathrm{r}=.208$, $\mathrm{p}<.000)$ ve genel saygı $(\mathrm{r}=.252, \mathrm{p}<.000)$ boyutları arasında pozitif yönde zayıf kuvvette anlamlı ilişkiler mevcuttur. İletişim ile sırası ile sosyal ( $\mathrm{r}=.108, \mathrm{p}=.047)$, ev-aile $(\mathrm{r}=.208, \mathrm{p}<.000)$, okul-akademik $(\mathrm{r}=.271$, $\mathrm{p}<.000)$ ve genel saygı $(\mathrm{r}=.163, \mathrm{p}=003)$ boyutları arasında pozitif yönde zayıf kuvvette anlamlı ilişkiler mevcuttur. Yabancılaşma ile sırası ile ev-aile $(\mathrm{r}=.135, \mathrm{p}=.012)$, okul-akademik $(\mathrm{r}=.249, \mathrm{p}<.000)$ ve genel sayg1 $(\mathrm{r}=.203, \mathrm{p}<.000)$ boyutları arasında pozitif yönde zayıf kuvvette anlamlı ilişkiler mevcuttur. Toplam bağlanma ile sırası ile sosyal $(\mathrm{r}=.127, \mathrm{p}=.018)$, ev-aile $(\mathrm{r}=.202, \mathrm{p}<.000)$, okul-akademik $(\mathrm{r}=.292, \mathrm{p}<.000)$ ve genel sayg1 $(\mathrm{r}=.247, \mathrm{p}<.000)$ boyutları arasında pozitif yönde zayıf kuvvette anlamlı ilişkiler mevcuttur.

\section{Sonuç ve Tartışma}

Bu araştırmada ortaokul öğrencilerinin annelerine bağlanma biçimleri ile benlik saygıları arsasındaki ilişki incelenmiştir. Kendilik algısının en önemli bileşenlerinden biri olarak benlik saygısının psikopatolojik rahatsızlıklara karşı koruyucu etkisi olduğuna ve anne ile bağlanmanın benlik saygısının öncülü olduğuna ilişkin raporlar mevuttur (Ainsworth, 1989; Cassidy, 1988; Keskin, 2014; Parker ve Benson, 2004; Paulusa ve diğerleri, 2018). Bu noktada anne ile kurulan sağliklı ilişki biçiminin çocuğun kişisel ve sosyal gelişimine katkısının göz ardı edilemeyecek boyutta olduğunu belirtmek yerinde olacaktır.

Çalışma kapsamında üç problem teste tabi tutulmuştur. Bu problemler, öğrencilerin annelerine bağlanma tarzlarının ve benlik saygılarının seviyesinin tespiti, bu değişkenlerin öğrencilerin sınıflarına ve cinsiyetlerin göre farklılaşıp farklılaşmadığının belirlenmesi ve öğrencilerin bağlanma tarzları ile benlik saygıları seviyesi arasındaki ilişkinin ortaya çıarılmasıdır. Elde edilen bulgulara göre öğrencilerin bağlanma seviyelerinin ve benlik saygılarının ortalama üzeri seviyede sağlıklı olma eğiliminde olduğu yönündedir. Öğrencilerin cinsiyetlerine göre herhangi bir farklılık bulunmamıştır. Öğrencilerin sınıflarına göre ise küçük çapta farklılıklar bulunmuştur. Öğrencilerin bağlanma tarzları ile benlik saygıları arasında önemli düzeyde ilişkiler tespit edilmiştir. 
Çalışmanın birinci problemi öğrencilerin anneye bağlılıklarının ve benlik saygılarının tespiti ile ilgilidir. Çocukların bağlanma derecelerinin güven, iletişim ve yabancılaşma olmak üzere üç farklı değişken üzerinden ölçüldüğü bu araştırmada öğrencilerin bağlanma derecelerinin ortalama üstü bir değere sahip olduğu bulunmuştur. Buna göre çocukların annelerine güven duydukları, anneleri ile iletişimlerinin iyi olduğunu ve anneleri ile ilişkilerinde yabancılaşma düzeyinin düşük olduğu belirtilebilir. Öğrencilerin benlik saygısı, genel özsaygı, sosyal özsaygı, ev-aile saygı ve okul-akademik özsaygı olmak üzere dört farklı boyut üzerinden değerlendirmeye tabi tutulmuştur. Çalışmaya katılan çocukların bütün alt boyutlardan ortalama üzere puan aldıkları tespit edilmiştir. Bu da öğrencilerin benlik saygılarının iyi durumda olduğu anlamına gelmektedir.

Çalışmamın ikinci problemi öğrencilerin cinsiyetlerine ve sınıflarına göre farklılaşıp farklılaşmadığı ile ilgilidir. Buna göre öğrencilerin cinsiyetlerine göre herhangi bir fark bulunmamıştır. Buna göre kız öğrencilerin ve erkek öğrencilerin anneye bağlanması ile benlik saygıları puanları arasında herhangi bir fark bulunmamaktadır. Cinsiyet ile ilgili bulgular Çelik (2007), Geniş (2017), Hazan ve Shaver (1987), Karademir (2015) ve Onur'un (2006) çalışmaları ile örtüşmektedir. Bahsi geçen araştırmalarda cinsiyetin bir farklılık yaratmadığı tespit edilmiştir. Buna karşın literatürde karşıt bulguları ifade eden çalışmalar da mevcuttur. Her ne kadar cinsiyetler arası farklılık bulan araştırmaların olduğu görülse de genel eğilimin farlılık olmadığı yönünde belirtmek gerekmektedir.

Öğrencilerin sınıflarına göre ise farklılıklar bulunmuştur. Buna göre bağlanma değişkeninde ve tüm alt boyutlarında 6. sınıfların daha yüksek puanlar elde ettikleri gözlemlenmiştir. Yaşları daha küçük olan bu katılımcıların anneleri ile daha sağlıklı bir ilişki içerisinde oldukları tespit edilmiştir. Yaş ilerledikçe ya da öğrencilerin sınıfları arttıkça anne ile bağlanma puanları bir başka ifade ile anne ile güvenli ilişkileri, iletişim düzeyleri azaltmakta ve anneye yabancılaşma artmaktadır. Bu bulgular literatürdeki çalışmalar ile fazla örtüşmemektedir. Kimi çalışmalar katılımcıların sınıflarına göre herhangi bir fark bulamazken, kimileri üst sınıfların daha sağlıklı bağlanma ilişkisi geliştirdiklerini bulmuşlardır (Diener, Isabella, Behunin ve Wong, 2008; Harter, 1998; Schneider, Atkinson ve Tardiff, 2001; Yersel, 2019). Küçük sınıftaki çocukların anneleri daha sağlıklı bağlanma ilişkisi geliştirmiş olmaları ile ilgili araştırmanın bu bulgusu alan yazın ile fazla örtüşmediği için özellikle ilginçtir ve konu ile ilgili yeni araştırmalar önemli katkı yapacaktır. Benlik saygısı seviyelerinde 8. sınıfların daha yüksek puanlara sahip olduğu belirlenmiştir. Buna göre 8. sınıfların genel özsaygıları, okul-akademik özsaygıları, ev-aile özsaygıları diğer sınıflara göre daha yüksektir.

Araştırmanın üçüncü problemi katılımcıların bağlanma puanları ile benlik saygıları arasındaki ilişki ile ilgilidir. Katılımcıların bağlanma ile benlik saygıları arasında olumlu ilişkiler tespit edilmiştir. İlişkilerin zayıf kuvvette olduğu gözlemlenmiştir. Alan yazında bağlanma ile benlik saygısı arasında pozitif ilişki bulan çalışmalar mevcuttur (Armsden ve Greenberg, 1987; Dede, 2015; Herz ve Gullone, 1999; Kenny, Lomax, Brabeck ve Fife, 1998; Noom, Dekovic ve Meeus, 1999; Wilkinson, 2004). Alan yazın dikkatli bir şekilde incelendiğinde bağlanma, özellikle anneye bağlanmanın, sağlıklı ve beklendik öğrenci davranışlarının ve psikolojik iyilik için öncül sayılabilecek benlik saygısının öncülü olduğu görülmektedir (Baltacı ve Altan, 2016; Öztürk, 2017). Bu çalışmada da anne ile geliştirilen güvene ve açık iletişime dayalı bir bağlanma tarzının çocukların benlik saygısı ile anlamlı pozitif bir ilişki gösterdiği gözlemlenmiştir. Buna karşın bağlanma ve benlik saygısı arasında negatif yönlü anlamlı ilişki tespit eden çalışmalara da alan yazında rastlanmaktadır. Başbekleyen (2018) zayıf da olsa anlamlı ve negatif bir ilişki bulmuştur.

Araştırma sonunda anneye bağlanma ile benlik saygısı arasında kuvvetli ve pozitif bir ilişki bulunmuştur. Bu bağlamda araştırmanın daha büyük örneklemlerle tekrarlanması sonuçların genellenmesine katkıda bulunabilir. Ayrıca farklı ve niş örneklemler ile bu tarz araştırmaların devam etmesi ilişkinin farklı sosyoekonomik ve kültürel gruplardaki çalışmasını test etme olanağı sunacaktır.

Bir diğer önemli husus ise anneye bağlanmanın benlik saygısının öncülü olması olgusu ile ilgilidir. Bu noktada pratiğe dönük ve etki yaratmayı hedefleyen programlara ihtiyaç olduğu düşünülmektedir. Özellikle annelere yönelik programlar bu noktada önem kazanmaktadır. Geliştirilecek programların annelerin çocukları ile sağlıklı bağlanma tarzı geliştirmesine yardımcı olacak şekilde tasarlanmalıdır. Bu bağlamda anne-çocuk bağlanma programlarının geliştirilmesine ve bu programların test edilmesine yönelik 
araştırmalara önemli derecede ihtiyaç olduğu düşünülmektedir. Okul rehberlik servisleri bu tür programlar geliştirmek ve uygulamak için ideal bir yer olarak gözükmektedir. Son olarak, yine okul rehberlik servislerinde benlik saygısını artırmaya yönelik çalışmaların yapılmasının oldukça önemli olduğu düşünülmektedir.

\section{Yazar(lar)ın Beyanı}

Araştırmacıların katkı oranı beyanı: Çalışma yazar tarafında gerçekleştirilmiştir.

Çatışma beyanı: Yazar herhangi bir çıkar çatışması olmadığını beyan eder.

Destek ve teşekkür: Araştırmanın gerçekleştirilmesi için herhangi bir kişi ya da kurumdan fon desteği alınmamıştır.

\section{Kaynaklar}

Ainsworth, M. D. S. (1989). Attachment beyond infancy. American Psychologist, 44(4), 709-716.

Ainsworth, M. D. S., Blehar, M., Waters, E. ve Wall, S. (1978). Patterns of attachment: A psychological study of the strange situation. Hillsdale, NJ: Erlbaum.

Armsden, G. C. ve Greenberg, M. T. (1987). The inventory of parent and peer attachment: Individual differences and their relationship to psycho- logical well-being in adolescence. Journal of Youth and Adolescence, 16(5), 427-454.

Baltacı, Ş. H. ve Altan, T. (2016). Lise öğrencilerinde benlik saygısının yordayıcısı olarak depresyon, bağlanma ve şiddet eğilimi. Mehmet Akif Ersoy Üniversitesi Eğiti Fakültesi Dergisi, 1(40), 227-239.

Başbekleyen, F. Z. (2018). Aile ve çocuk arasındaki güvensiz bağlanmanın, ortaokul son sını öğrencilerinde benlik algısı, sosyal anksiyete, depresif belirtileri arasındaki ilişkinin incelenmesi (Yüksek lisans tezi). İstanbul Gelişim Üniversitesi, Sosyal Bilimler Enstitüsü, İstanbul.

Bowlby, J. (1977). The making and breaking of affectional bonds in: A etiology and psychopathology in the light of attachment theory. British Journal of Psychiatry, 130(3), 201-210.

Bowlby, J. (1982). Attachment and loss. New York: Basic Books.

Bowlby, J. (1988). A secure base: Parent-child attachment and healthy human development. New York: Basic Books.

Burke, R. J. ve Weir, T. (1978). Benefits to adolescents of helping relationships with parents and peers. Psychological Reports, 42(3), 1175-1184.

Cassidy, J. (1988). Child-mother attachment and the self in six-year-olds. Child Development, 59(1), 121-134. doi:10.2307/1130394.

Coopersmith, S. (1967) The Antecedents of self-esteem. San Francisco: Freeman and Company.

Çelik, G. (2007). Çocuk ve ergen ruh sağlığı ve hastalıkları kliniğine başvuran ergenlerin özellikleri (Uzmanlık Tezi). Çukurova Üniversitesi, Tip Fakültesi, Adana.

Dede, F. (2015). Lise öğrencilerinin çatışma çözme yaklaşımlarının bağlanma stilleri ve bazı değiş̧kenler açısından incelenmesi (Yayımlanmamış yüksek lisans tezi). Çukurova Üniversitesi, Adana.

Demirtaş, A. S. (2019). Erken ergenlikte güvenli bağlanma ve öz-yeterlik: Umudun aracı rolü. Eğitim ve Bilim, 44(200), 175-190.

Diener, M. L., Isabella, R. A., Behunin, M. G. ve Wong, M. S. (2007). Attachment to mothers and fathers during middle childhood: Associations with child gender, grade, and competence. Social Development 17(1), 84-101. doi:10.1111/j.1467-9507.2007.00416.x

Geniş, N. E. (2017). Okul öncesi dönem çocuklarında bağlanma ve benlik algısı iliş̧isinin incelenmesi (Yüksek lisans tezi). Karabük üniversitesi, Sağlık Bilimler Enstitüsü, Karabük. 
Giedd, J. N., Blumenthal, J., Jeffries, N. O., Castellanos, F. X., Liu, H., Zijdenbos, A., . . Rapoport, J. L. (1999). Brain development during childhood and adolescence: A longitudinal MRI study. Nature Neuroscience, 2(10), 861-863. doi: 10.1038/13158

Graybill, D. (1978). Relationship of maternal child-rearing behaviors to children's self-esteem. The Journal of Psychology, 100(1), 45-47. doi: 10.1080/00223980.1978.9923469

Guarnieri, S., Ponti, L. ve Tani, F. (2010). The inventory of parent and peer attachment (IPPA): A study on the validity of styles of adolescent attachment to parents and peers in an Italian sample. TPM Vol. 17(3), 103-130.

Güçray, S. (1989). Çocuk yuvasında ve ailelerinin yanında kalan 9-10-11 yaşlarındaki çocukların benlik saygısını etkileyen bazı faktörler (Yayımlanmamış doktora tezi). Hacettepe Üniversitesi, Ankara.

Güloğlu, B. ve Aydın, G. (2001). Coopersmith Özsaygı Envanteri'nin faktör yapısı. Eğitim ve Bilim, 26(122), 66-71.

Günaydın, G., Selçuk, E., Sümer, N. ve Uysal, A. (2005). Ebeveyn ve arkadaşlara bağlanma envanteri kısa formunun psikometrik açıdan değerlendirilmesi. Türk Psikoloji Yazıları, 8(16) 13-23.

Harter, S. (1998). The development of self-representations. W. Damon (Seri Ed.) ve N. Eisenberg (Sayı Ed.), Handbook of child psychology: Vol. 3: Social, emotional, and personality development (5. bs.)(s. 553-617) içinde. New York: Wiley.

Harter, S. (2012). The construction of the self: Developmental and sociocultural foundations. New York: Guilford Press.

Hazan, C. ve Shaver, P. (1987). Romantic love conceptualized as an attachment process. Journal of Personality and Social Psychology, 52(3), 511-24.

Herz, L. ve Gullone, E. (1999). The relationship between self-esteem and parenting style: A cross-cultural comparison of Australian and Vietnamese Australian adolescents. Journal of Cross-Cultural Psychology, $30(6), 742-761$.

Karademir, N. (2015). Fen edebiyat fakültesi coğrafya bölümü öğrencilerinin özgüven algıları. Kahramanmaraş Sütçü İmam Üniversitesi Sosyal Bilimler Dergisi, 12(2), 53-77.

Kenny, M. E., Lomax, R., Brabeck, M. ve Fife, J. (1998). Longitudinal pathways linking adolescent reports of maternal attachment and paternal attachment to psychological well-being. Journal of Early Adolescence, 18(3), 221-243.

Keskin, P. S. (2014). Anne işte çalışan anne ve çocuğu. İstanbul: Boyut Yayınc1lı.

Kobak, R. R. ve Sceery, A. (1988). Attachment in late adolescence: Working models, affect regulation, and representation of self and others. Child Develop, 59(1), 135-146.

Mert, K. ve Tamer A. (2019). Effects of the tell me about me program: Perception of social support, self-esteem, and self-compassion in older adults. Journal of Gerontological Nursing, 45(10), 39-46. doi:10.3928/0098913420190825-03

Milli Eğitim Bakanlığı. (2019). Milli Eğitim istatistikleri: Örgün Eğitim. TUiK: Ankara.

Mikulincer, M. ve Shaver, P. R. (2007). Attachment in adulthood: Structure, dynamics, and change. New York, NY: Guilford Press.

Naveh-Benjamin, M., Shing, Y. L., Kilb, A., Werkle-Bergner, M., Lindenberger U. ve Li, S. (2009). Adult age differences in memory for name-face associations: The effects of intentional and incidental learning. Memory, 17(2), 220-232. doi: 10.1080/09658210802222183

Noom, M. J., Dekovic, M. ve Meeus, W. H. J. (1999). Autonomy, attachment, and psychosocial adjustment during adolescence: A double-edged sword? Journal of Adolescence, 22(6), 771-783. 
Onur, N. (2006). Lise Öğrencilerinin bağlanma şekilleri ile atılganlık düzeyleri arasındaki ilişki (Yayınlanmamış yüksek lisans tezi). Marmara Üniversitesi, Eğitim Bilimler Enstitüsü, İstanbul.

Öztürk, N. (2017). Üniversite öğrencilerinin algıladıkları aile iklimi ve anne-babaya bağlanma biçimleri ile özgüven düzeyleri arasındaki ilişkinin incelenmesi. The Journal of International Lingual, Social and Educational Sciences, 3(1), 9-22.

Parker, J. S. ve Benson, M. J. (2004). Parent-adolescent relations and adolescent functioning: Self-esteem, substance abuse, and delinquency. Adolescence, 39(155), 519-530.

Paterson, J., Pryor, J. ve Field, J., 1995. Adolescent attachment to parents and friends in relation to aspects of self-esteem. Journal of Youth and Adolescence, 24(3), 365-376.

Paulusa, M., Licata, M., Gniewosz, B. ve Sodian, B. (2018). The impact of mother-child interaction quality and cognitive abilities on children's self-concept and self-esteem. Cognitive Development, 48, 42-51. doi:10.1016/j.cogdev.2018.07.001

Raja, S. N., McGee, R. ve Stanton, W. R. (1992). Perceived attachments to parents and peers and psychological well-being in adolescence. Journal of Youth and Adolescence, 21(4), 471-485.

Rosenberg, M. (1965). Society and the adolescent self-image. Princeton: Princeton University Press.

Schneider, B. H., Atkinson, L. ve Tardif, C. (2001). Child-parent attachment and children's peer relations: A quantitative review. Developmental Psychology, 37(1), 86-100.

Soysal. Ş, Bodur, Ş., İşleri, E. ve Şenol, S. (2005). Bebeklik döneminde bağlanma sürecine genel bir bakış. Klinik Psikiyatri, 8(2), 88-99.

Suzuki, H. ve Tomoda, A. (2015). Roles of attachment and self-esteem: impact of early life stress on depressive symptoms among Japanese institutionalized children. BMC Psychiatry, 15(8). doi: 10.1186/s12888-0150385-1

Thompson, R. A. (2008). Early attachment and later development: Familiar questions, new answers. J. Cassidy ve P. R. Shaver (Ed.), Handbook of attachment (2. bs.) (s. 348-365) içinde. New York: Guilford.

Turan N. ve Tufan B. (1987, Eylül). Coopersmith Benlik Saygısı Envanteri'nin (SEI) geçerlik-güvenirlik çalışması. İstanbul 23. Ulusal Psikiyatri ve Nörolojik Bilimler Kongresi Bilimsel Çalışmaları (Kongre Kitabı). İstanbul.

Varghese, M.E. ve Pistole, M.C. (2017). College student cyberbullying: Self-esteem, depression, loneliness, and attachment. Journal of College Counseling, 20(1), 7-21. doi:10.1002/jocc.12055

Wilkinson, R. B. (2004). The role of parental and peer attachment in the psychological health and self-esteem of adolescents. Journal of Youth and Adolescence, 33(6), 479- 493.

Williams, C. (2007). Research methods. Journal of Business \& Economics Research (JBER), 5(3), 65-72. doi:10.19030/jber.v5i3.2532

Yersel Z. (2019). Çocuk ve ergenlerde anne-baba tutumu ve bağlanma durumunun algıladıkları benlik saygısı ve çocukluk çă̆̆ narsisizmï ile ilişkisi (Yayınlanmamış yüksek lisans tezi). Beykent Üniversitesi, İstanbul.

Yörükoğlu, A. (1996). Gençlik çağı: Ruh să̆hlğı ve ruhsal sorunlar. Ankara: Özgür Yayınları. 


\section{EXTENDED ABSTRACT}

\section{Introduction}

Attachment studies emerge as a very deeply researched field since the theoretical framework developed by Bowlby $(1977 ; 1988)$. Attachment in both children and adults has been addressed in depth and from different perspectives (Cassidy, 1988; Demirtaş, 2019; Günaydın, Selçuk, Sümer, and Uysal, 2005; Kobak and Sceery, 1988; Mikulincer and Shaver, 2007; Paterson, Pryor, and Fiedl, 1995; Suzuki and Tomada, 2015; Varghese and Pistole, 2017). Although the findings of all studies are different, the common point is that attachment style has important effects on both children and adults. The concept of self-esteem, which is another problematic of this study, emerges as a subject whose effects are examined from various perspectives. Self-esteem is reported to have a positive correlation with and mediation effects on many different positive concepts (Demirtaş, 2019; Güloğlu and Aydın, 2001; Mert and Tamer, 2019; Suzuki and Tomada, 2015; Wilkinson, 2004). Attachment and self-esteem appear as factors that deeply affect psychological well-being and personality development. This study examines the relationship between these two concepts.

Family is one of the most important variables that affect individual's development of self-perception. According to attachment theory, attachment, especially attachment to mother, has important effects on selfesteem (Ainsworth, 1989; Burke and Weir, 1978). There are studies reporting that safe attachment has a protective effect against psychopathological disorders and contributes to the development of acceptable selfesteem (Cassidy, 1988; Parker and Benson, 2004). In studies that deal with the relationship between attachment and self-esteem, the quality of the relationship with the mother comes into prominence (Cassidy, 1988; Graybill, 1978; Raja, et al., 1992; Paulusa, Licata, Ginewosz and Sodian, 2018). Therefore, the quality of the relationship with the mother is the precursor of self-esteem. This study tests this assumption. Considering the role of self-esteem in personality development, determining its precursor seems quite important. In this context, the main purpose of this research is to determine the self-esteem of the individuals and the relationship to mother how these two concepts correlate. For this purpose, the following questions are included in the scope of the research;

1. How do middle school students connect to their mother?

2. What is the level of self-esteem of middle school students?

3. Do middle school students' attachment styles and self-esteem levels differ according to their gender and class?

4. Is there a meaningful relationship between middle school students' attachment style and self-esteem levels?

\section{Method}

This study is correlational one that investigates the relationship between middle school students' maternal attachment and self-esteem level. The population of this study is students who attend public middle school in Istanbul. A total of 400 sample of students is randomly selected from three different districts of Istanbul. This study uses two different scales to collect data, which are the Turkish versions of Coopersmith self-esteem scale and of attachment scale developed by Raja et al. (1992). Collected data is analyzed by utilizing independent sample t-test, ANOVA and Pearson Correlation Momentum.

\section{Results}

Regarding the first problem of the study, it is found out that students have a mean of attachment better than the average. Similarly, the self-esteem of students is better than the average. Regarding the second problem of the study, it is found out there are not any significant differences in students' maternal attachment quality and self-esteem levels with respect to their gender. There are differences per grade level. Students who are attending 6. grade have a higher maternal attachment than the students who are attending 7. and 8. grades. As for the self-esteem, it has been found that students who are attending 8. grades have a higher level of selfesteem than the other students. Regarding the last problem of the study, correlations positive in direction and 
weak in magnitude have been found. Accordingly, there are positive correlations between maternal attachment and self-esteem and among all of the dimensions of scales.

\section{Conclusion}

The study examines the relationship between middle school students' maternal attachment and selfesteem. Accordingly, this study has found out that students have a mean score of maternal attachment and self-esteem higher than the average score. Based on this, it can be indicated that students have a secure attachment to their mothers, and similarly, they have a healthy level of self-esteem. Students' gender is not a factor in their scores of maternal attachment and self-esteem. Their grade level seems to be a factor in their scores. Students' maternal attachment and self-esteem have positive correlations.

There is a great deal of research in the literature on attachment and self-esteem. Although it is important to continue this kind of research with different and niche samples, it is thought that there is a need for developing programs aiming to create an impact. Programs especially aiming for mothers gain importance at this point. The programs should be designed to help mothers to develop a healthy attachment style with their children. In this context, it is considered that there is a great need for researches for developing mother-child attachment programs and testing these programs. 